\title{
ECLETICA
}

www.scielo.br/eq

Volume 32, número 2, 2007

\section{Evaluation of a carbon paste electrode modified with organofunctionalised SBA-15 silica in the determination of copper}

\author{
I. Cesarino ${ }^{\prime}$; G. Marino ${ }^{I}$; J.R. Matos ${ }^{I I}$; E.T. G. Cavalheiro ${ }^{I, *}$ \\ ${ }^{I}$ Inst. de Química de São Carlos, Univ. de São Paulo, P.O. Box 780, 13560-970 São Carlos - SP, Brasil \\ ${ }^{I I}$ Dep. de Química Fundamental, Universidade de São Paulo, Cidade Universitária Armando Salles Oliveira, \\ São Paulo/SP
}

*cavalheiro@iqsc.usp.br

\begin{abstract}
The performance of a carbon paste electrode (CPE) modified with SBA-15 nanostructured silica organofunctionalised with 2-benzothiazolethiol for determination of $\mathrm{Cu}(\mathrm{II})$ ions in sugar cane spirit ( cachaça) is described, based on differential pulse anodic stripping voltammetry (DPASV) procedure. $\mathrm{The} \mathrm{Cu}$ (II) oxidation peak was observed at $-0.03 \mathrm{~V}$ (vs. SCE) in phosphate solution (pH 3.0). The results were obtained using optimised conditions such as $100 \mathrm{mV}$ pulse amplitude, 3 min accumulation time, 25 $\mathrm{mV} \mathrm{s}^{-1}$ scan rate in phosphate solution $\mathrm{pH} 3.0$, resulting in a linear dynamic range from $8.0 \times 10^{-7}$ to $1.0 \mathrm{x}$ $10^{-5} \mathrm{~mol} \mathrm{~L}^{-1} \mathrm{Cu}(\mathrm{II})$ and a limit of detection $2.0 \times 10^{-7} \mathrm{~mol} \mathrm{~L}^{-1} \cdot \mathrm{Cu}(\mathrm{II})$ spiked in a cachaça sample was determined with $102.5 \%$ mean recovery at $\mathrm{mmol} \mathrm{L}^{-1}$ level. Interference from other metallic cations present in the sample was avoided by the standard addition procedure.
\end{abstract}

Keywords: SBA-15 nanostructured silica; Carbon paste electrode; 2-Benzothiazolethiol; Copper(II).

\section{Introduction}

The application and unusual properties of nanomaterials made them a growing interest issue in contemporaneous science. The ability of surfactants to self-assemble into well-defined structures has been taken advantage for the design and synthesis of inorganic materials with nanosized dimensions. The distinction between these materials is based on the mechanisms involved in the synthesis, the $\mathrm{pH}$, the templates used, the topology and the pore architecture [1]. Examples are materials such as MCM-41, MCM-48 and SBA-15 first reported in the early 1990's has lead to a whole new class of materials with high mechanical and thermal stability. SBA-15 presents an hexagonally ordered cylindrical nanochannels, uniform pore sizes up to approximately $300 \AA$ [2] and large surface area. These features made it subject of several investigation and used in many applications since it has first reported by Zhao et al. [3].

Ecl. Quím., São Paulo, 32(2): 29-34, 2007
Chemical functionalisation of the inorganic framework of porous materials through the covalent coupling of an organic moiety is a promising approach for preparing porous surfaces having specific properties allowing many applications in chemistry [4-6]. In analytical chemistry such materials can be applyed in improvement of selectivity and sensitivity in the preparation of electrodes for electroanalysis and pre-concentration and separation of chemistry species.

Walcarius $[7,8]$ present extensive reviews about the preparation and application of silica modified electrodes showing their importance as electroanalytical sensors.

Carbon paste electrodes modified with functional ligands have been more widely used to pre-concentrate and quantify trace metal ions [912].

Trace metal voltammetric analysis is of great interest in the literature mainly in environmental samples due to the sensitivity, 
simplicity, speed and low cost in comparison to other instrumental methods [13-15].

Copper is an essential element at trace level (i.e. catalytic action in heme synthesis) [16], but the intake of large quantities can be toxic. Sources of copper poisoning include beverages from vending machines, copper or brass vessels, and sometimes water supplies. Monitoring of $\mathrm{Cu}$ (II) concentration is also becoming important in microelectronics fabrication industry [17]. Thus, the development of simple and low cost techniques for trace copper determination is essential.

According to Brazilian regulations, it may be sold raw or with addition of sugar and may contain up to $5 \mathrm{mg} \mathrm{L}^{-1}$ of copper [18]. Determination of trace amounts of zinc, lead and copper in sugar cane spirits have been proposed based on anodic stripping voltammetry with a hanging mercury drop [19]. Another work proposed the determination of copper in sugar cane rum by cyclic voltammetry using carbon paste electrode modified with humic acids [20].

In the present work, the use of organofunctionalised SBA-15 silica with 2benzothiazolethiol in the preparation of carbon paste electrodes is described. SBA-15 silica presented the advantage of no need of surface pre-treatment before modification when compared with silica gel usually employed in such methods. The best conditions for a differential pulse anodic stripping voltammetric (DPASV) procedure were optimised and the electrode was applied in the determination of $\mathrm{Cu}$ (II) in a sugar cane spirit (cachaça) sample with good agreement with atomic absorption spectrometry (AAS). This matrix was chosen considering its large consumption in Brazil and the usage of copper apparatus for the distillation.

\section{Experimental details} Apparatus

All the voltammetric measurements were carried out on $20 \mathrm{ml}$ capacity thermostated glass cell at $25^{\circ} \mathrm{C}$, using a carbon-paste modified with SBA-15 silica organofunctionalised with 2benzothiazolethiol (BTPSBA-MCPE) as a working, saturated calomel as reference (SCE) and platinum wire as auxiliary electrodes. High purity nitrogen
(FID. 4.9 AGA) was used for deaeration of the electrolyte solution. DPASV were performed in BAS CV - 50W Voltammetric Analyzer (Bioanalytical Systems) controlled by the BAS $50 \mathrm{~W}$ windows control software, v. 2.3 (Bioanalytical Systems).

\section{Reagents and solutions}

All the solutions were prepared with water purified in a Millipore Milli-Q system. All the chemicals were of analytical grade and used without further purification. The supporting electrolyte used for most experiments was a 0.10 mol L-1 phosphate solution $\mathrm{pH}$ 3.0. Stock solution containing $1.00 \times 10^{-3} \mathrm{~mol} \mathrm{~L}^{-1} \mathrm{Cu}$ (II) was prepared daily by dissolving an appropriate amount of a $1000 \mathrm{mg} \mathrm{L}^{-1}$ reference copper nitrate solution (Tec$\mathrm{Lab}$ ) in $100 \mathrm{ml}$ of the $0.10 \mathrm{~mol} \mathrm{~L}^{-1}$ phosphate solution pH 3.0.

The 3-(Chloropropyl)-trimethoxysilane (Aldrich) and 2-benzothiazolethiol (Sigma) were used in the functionlization of the SBA-15 silica.

A 1-2 mm particle size graphite powder (Aldrich) and mineral oil (Aldrich) were used for the preparation of the carbon pastes.

Preparation of the organofunctionalised SBA15 silica and the modified carbon paste electrodes

The SBA-15 silica was synthesized according to a previously described procedure [21]. SBA-15 silica with a large surface area $\left(>1500 \mathrm{~m}^{2} \mathrm{~g}\right.$ $\left.{ }^{1}\right)$ and large pore volumes $\left(>1 \mathrm{~cm}^{3} \mathrm{~g}^{-1}\right)$ was used without further treatment, in a procedure described earlier [22,23].

Modified carbon paste electrodes (MCPE) were prepared by mixing the graphite powder with BTPSBA. The mixture was added to $0.250 \mathrm{~g}$ of mineral oil and mixed on mortar for at least $20 \mathrm{~min}$ to produce the final paste in order to each electrode containing $10,15,20$ and $25 \%$ of BTPSBA, $w / w$. The carbon paste electrode was finally obtained by packing the paste into a plastic tube $4.5 \mathrm{~mm}$ i.d. (geometrical area $0.16 \mathrm{~cm}^{2}$ ) and arranged with a copper wire serving as an external electric contact. Appropriate packing was achieved by pressing the electrode surface against a bond paper until a smooth surface was obtained.

Sample preparation and analysis of copper in sugar cane spirit (cachaça) 
To a $10.0 \mathrm{ml}$ aliquot of sugar cane spirit (Sant 'Antonio brand) it was added $1.0 \mathrm{ml}$ of 0.1 mol L-1 nitric acid. Then $1.0 \mathrm{ml}$ of this sample was mixed with $10.0 \mathrm{ml}$ of $0.1 \mathrm{~mol} \mathrm{~L}^{-1}$ phosphate solution $\mathrm{pH}$ 3.0. The $\mathrm{Cu}(\mathrm{II})$ content in that sample was determined by three successive addition of a standard copper(II) solution.

Atomic absorption spectrometry determinations were performed in spectrofotometry HITACHI Z-8100, using cathode lamp and lamp current of $7.5 \mathrm{~mA}$, the wavelength of $324,8 \mathrm{~nm}, \mathrm{C}_{2} \mathrm{H}_{2}$ flow rate of 2,2 $\mathrm{L} \mathrm{min}^{-1}$ and airacetilene flame.

\section{Results and Discussion}

Differential pulse anodic stripping voltammetry (DPASV)

DPASV of $3.0 \times 10^{-5} \mathrm{~mol} \mathrm{~L}^{-1} \mathrm{Cu}$ (II) solution in $0.1 \mathrm{~mol} \mathrm{~L}^{-1}$ phosphate solution $\mathrm{pH} 3.0$, showed one anodic peaks at the potential -0.03 V (vs. SCE). Parameters such as accumulation potential and time, scan rate, supporting electrolyte, $\mathrm{pH}$, electrode composition that affects the voltammetric peak current were optimized as described in Table 1.

The effect of the carbon paste composition in the voltammetric response of the electrode modified with BTPSBA was evaluated by DPASV of $3.00 \times 10^{-5} \mathrm{~mol} \mathrm{~L}^{-1} \mathrm{Cu}$ (II) in $0.1 \mathrm{~mol} \mathrm{~L}^{-1}$ phosphate

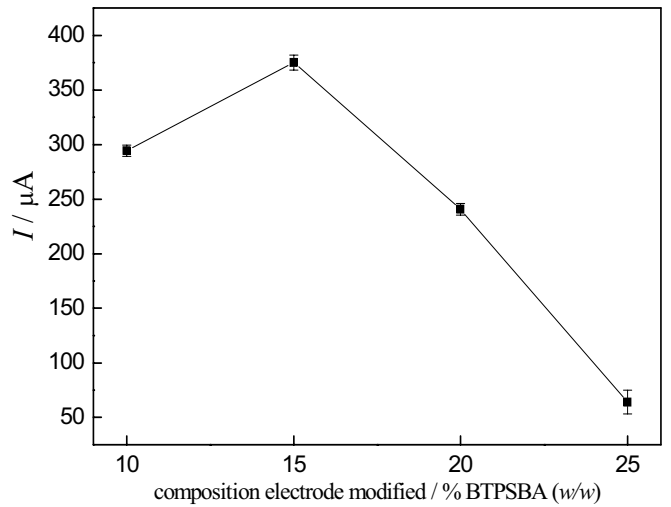

Figure 1. Carbon paste composition modified with 10, 15,20 and $25 \%$ BTPSBA $(w / w)$ obtained with scan rate of $25 \mathrm{mV} \mathrm{s}^{-1}$, pulse amplitude of $100 \mathrm{mV}$, accumulation potential and time $-0.80 \mathrm{~V}, 180 \mathrm{~s}$ and potential interval 0.80 to $+0.60 \mathrm{~V}$ (vs. SCE)

solution $\mathrm{pH} 3.0$ (Figure 1). The anodic peak current increased with the amount of organofunctionalised SBA-15 silica in the paste up to $15 \%(w /$ $w)$,decreasing significantly when more modified silica is used in the electrode preparation. This probably occurs due to a decrease in the conductive area at the electrode surface. According to these results a carbon-paste composition of $15 \%$ $(w / w)$ modified SBA-15 silica, 60\% $(w / w)$ graphite and $25 \%(w / w)$ mineral oil was employed.

Table 1. Optimum parameters for determination of copper(II) using the carbon paste electrode modified with organofunctionalised SBA-15 silica with 2-benzothiazolethiol in differential pulse anodic stripping voltammetry

\begin{tabular}{cc}
\hline Parameter & Optimized value \\
\hline Scan rate & $25 \mathrm{mV} \mathrm{s}^{-1}$ \\
Pulse amplitude & $100 \mathrm{mV}$ \\
Accumulation potential and time & $-0.8 \mathrm{~V}($ vs. SCE), $180 \mathrm{~s}$ \\
Potential interval & -0.80 to $+0.60 \mathrm{~V}(\mathrm{vs} . \mathrm{SCE})$ \\
Electrode composition & $15 \%(w / w)$ modified SBA-15 silica, \\
& $60 \%(w / w)$ graphite, \\
& $25 \%(w / w)$ mineral oil \\
Supporting electrolyte and $\mathrm{pH}$ & $0.10 \mathrm{~mol} \mathrm{~L}^{-1}$ phosphate solution and $\mathrm{pH} 3.0$ \\
\hline
\end{tabular}


Comparison of the voltammetric behavior of Cu(II) on carbon paste and silica modified electrodes

Fig. 2 presents the differential pulse anodic stripping voltammograms obtained with unmodified carbon paste electrode, SBA-15 silica and organofunctionalised SBA-15 silica modified carbon paste electrodes in $0.10 \mathrm{~mol} \mathrm{~L}^{-1}$ phosphate solution $\mathrm{pH}$ 3.0. No peaks were observed in the potential range -0.80 to $+0.60 \mathrm{~V}$ (vs. SCE) for phosphate solution at the BTPSBA-MCPE (curve a) in the absence of $\mathrm{Cu}(\mathrm{II})$.

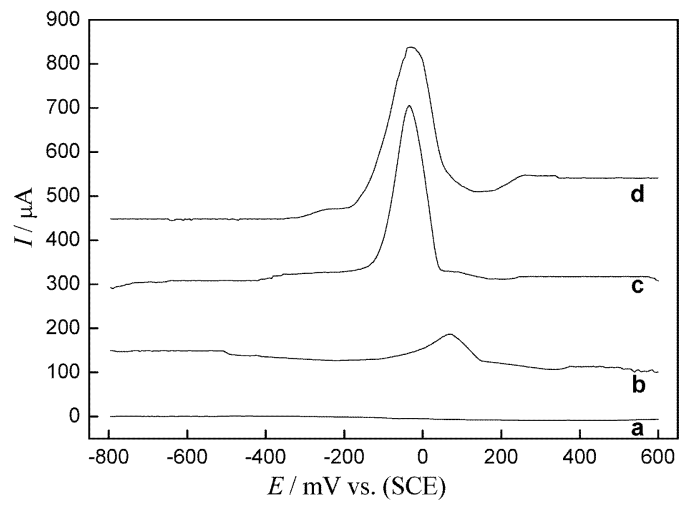

Figure 2. Differential pulse anodic stripping voltammograms obtained at $25^{\circ} \mathrm{C}$, scan rate of $25 \mathrm{mV} \mathrm{s}^{-}$ ${ }^{1}$, pulse amplitude of $100 \mathrm{mV}$ and pulse width of $50 \mathrm{~ms}$ for (a) BTPSBA-MCPE in the presence only the $0.10 \mathrm{~mol} \mathrm{~L}^{-}$ ${ }^{1}$ phosphate solution $\mathrm{pH} 3.0$, (b) unmodified electrode in the presence of $3.0 \times 10^{-5} \mathrm{~mol} \mathrm{~L}^{-1} \mathrm{Cu}(\mathrm{II})$, (c) BTPSBAMCPE in the presence of $3.0 \times 10^{-5} \mathrm{~mol} \mathrm{~L}^{-1} \mathrm{Cu}(\mathrm{II})$ and (d) SBA-15-MCPE in the presence of $3.0 \times 10^{-5} \mathrm{~mol} \mathrm{~L}^{-1} \mathrm{Cu}(\mathrm{II})$. Potential interval -0.80 to $+0.60 \mathrm{~V}$ (vs. SCE), accumulation potential and time $-0.80 \mathrm{~V}, 180 \mathrm{~s}$.
However, when the accumulation process was carried out for $180 \mathrm{~s}$ at $-0.80 \mathrm{~V}$ in solution containing $3.0 \times 10^{-5} \mathrm{~mol} \mathrm{~L}^{-1} \mathrm{Cu}$ (II) at the unmodified carbon paste electrode (curve b), the $\mathrm{Cu}(0)$ oxidation peak appears at $+0.07 \mathrm{~V}$.

The same solution exhibits a peak at -0.03 $\mathrm{V}$ when the SBA-15-MCPE (curve d) is used. At the BTPSBA-MCPE (curve c) the oxidation peak also appears at $-0.03 \mathrm{~V}$ with higher intensity of the anodic currents in comparison to those observed at other electrodes. The currents were measured from the shoulder-to-shoulder baseline to the peak at of maximum signal.

Analytical curve, precision, detection limit and recovery in buffer solutions

Analytical curve for $\mathrm{Cu}(\mathrm{II})$ is presented in Fig. 3 under the set of optimum conditions resumed in Table 1. The anodic peak current at the BTPSBA-MCPE increased linearly with the concentration of the $\mathrm{Cu}$ (II) in a range from $8.0 \times 10^{-}$ ${ }^{7}$ to $1.0 \times 10^{-5} \mathrm{~mol} \mathrm{~L}^{-1}$ with a limit detection of $2.0 \times 10^{-}$ ${ }^{7} \mathrm{~mol} \mathrm{~L}^{-1}$ (three times the signal blank/slope) [24]. The linear regression equation (see detail in Fig. 3) is:

$$
\mathrm{I}_{\mathrm{a}}=2.51 \times 10^{-6}+6.88 \mathrm{C}_{\mathrm{Cu}}{ }^{2+} ; \mathrm{r}=0,997 ; \mathrm{n}=6
$$

The present electrode can be used without resurfacing or activation between successive determinations and with a relatively low pre-concentration time, when compared with other methods.

\begin{tabular}{|c|c|c|}
\hline Interferant & Concentration $/ 10^{-6} \mathrm{~mol} \mathrm{~L}{ }^{-1}$ & $(\%)$ of $\mathrm{Cu}(\mathrm{II})$ signal ${ }^{*}$ \\
\hline $\mathrm{Zn}^{2+}$ & $\begin{array}{c}2.5 \\
5.0 \\
10.0\end{array}$ & $\begin{array}{l}132.4 \\
156.6 \\
154.3\end{array}$ \\
\hline $\mathrm{Co}^{2+}$ & $\begin{array}{c}2.5 \\
5.0 \\
10.0\end{array}$ & $\begin{array}{l}85.3 \\
76.5 \\
81.8\end{array}$ \\
\hline $\mathrm{Cd}^{2+}$ & $\begin{array}{c}2.5 \\
5.0 \\
10.0\end{array}$ & $\begin{array}{c}113.3 \\
90.9 \\
90.5\end{array}$ \\
\hline $\mathrm{Mn}^{2+}$ & $\begin{array}{c}2.5 \\
5.0 \\
10.0\end{array}$ & $\begin{array}{l}86.2 \\
77.5 \\
70.5\end{array}$ \\
\hline
\end{tabular}




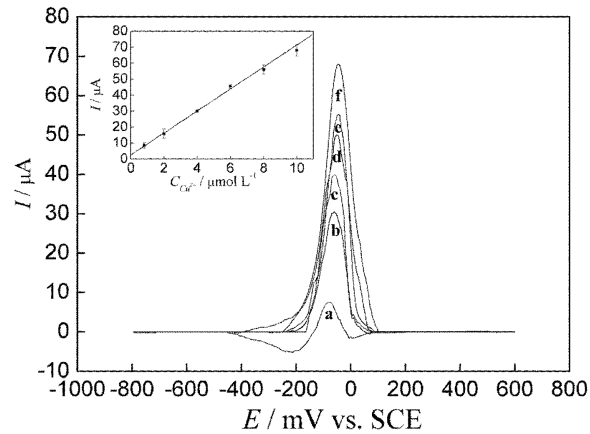

Figure 3. Differential pulse anodic voltammograms obtained in phosphate solution: a) 8,00 ; b) 20,0; c) $40,0$; d) 60,0 ; e) $80,0 \mathrm{f}) 100 \times 10^{-7} \mathrm{~mol} \mathrm{~L}^{-1} \mathrm{Cu}$ (II). The analytical curve is shown in the detail. Other conditions as in Figure 1 caption.

\section{Interferences}

The influence of $\mathrm{Zn}(\mathrm{II}), \mathrm{Co}(\mathrm{II}), \mathrm{Cd}(\mathrm{II})$ and $\mathrm{Mn}(\mathrm{II})$ in the $\mathrm{Cu}(\mathrm{II})$ anodic peak current has been evaluated and the results are presented in Table 2. Severe suppression of the $\mathrm{Cu}(\mathrm{II})$ current is observed in the presence of $\mathrm{Co}$ (II) and $\mathrm{Mn}$ (II), while the presence of $\mathrm{Zn}(\mathrm{II})$ causes a significant increase in the $\mathrm{Cu}$ (II) current. The presence of $\mathrm{Cd}$ (II) in concentrations lower than the $\mathrm{Cu}$ (II) causes an increase in the response, while at equal or higher concentrations the interferant leaded to a decrease in the analyte signal. In all the cases the interference looks to reach a constant level at interferant concentrations higher than the analyte.

However the separation of the peaks suggests that a simultaneous analysis of some of these cations can be performed and that the interference may be bypassed using standard addition procedures.
Analysis of copper in sugar cane spirit

The proposed electrode was applied for DPASV determination of $\mathrm{Cu}$ (II) in cachaça sample using the optimised conditions. The $\mathrm{Cu}$ (II) content in the cachaça was previously determined by AAS as being $3.97 \mathrm{mg} \mathrm{L}^{-1}\left(6.24 \times 10^{-5} \mathrm{~mol} \mathrm{~L}^{-1}\right)$. This analysis was performed at "Laboratório para o Desenvolvimento da Química de Aguardente" do IQSC/USP.

The results obtained using the standard addition method is presented in Table 3 . Recoveries between 98.0 and $107.0 \%$ de $\mathrm{Cu}$ (II) from cachaça sample ( $\mathrm{n}=3$ ) was obtained, for 2.00, 3.92, $5.77 \mathrm{mmol}$ $\mathrm{L}^{-1}$ de $\mathrm{Cu}(\mathrm{II})$. These recoveries were found measuring the added amount of copper discounted the originally present concentration according to the AAS data.

Statistical calculations for the results showed suitable precision of the proposed method. According to the t-Student, there were no significant differences between AAS and the proposed method at the $95 \%$ confidence level, indicating that carbon paste electrode modified with BTPSBA can be used for voltammetric determinations of $\mathrm{Cu}(\mathrm{II})$ in cachaça samples. The statistical calculations were performed taking the AAS value as a "know" value as described by Harris [25].

So, the use of the standard addition procedure in order to avoid interference from the metallic cations present in the beverage samples proved to be a successful strategy.

Table 3. Determination of copper in cachaça by proposed method

\begin{tabular}{c|ccc}
\hline Replicate & \multicolumn{2}{|c}{$\mathbf{C}_{\mathbf{C u 2}+} / \mathbf{~ m g ~ L}^{-1}$} & $\mathbf{E}_{\mathbf{r}} / \%$ \\
\hline \multirow{2}{*}{1} & AAS & DPASV \\
2 & 3,97 & $4,23 \pm 0.15$ & $+6,5$ \\
3 & - & $3,84 \pm 0.10$ & $-3,3$ \\
& - & $3,92 \pm 0.13$ & $-1,3$ \\
& & Mean $=4,00 \pm 0,20$ & \\
\hline
\end{tabular}

AAS - atomic absorption spectrometry

DPASV - differential pulse anodic stripping voltammetry 


\section{Conclusion}

The use of the organofunctionalised SBA-15 silica with 2-benzothiazolethiol for preparation of modified carbon paste electrodes could be used in the electroanalytical determination of $\mathrm{Cu}$ (II) for concentration in the ìmol $\mathrm{L}^{-1}$ level. Reproducible results that agree with those from AAS were obtained in a relatively fast, low cost and sensitive analysis without need of time consuming sample preparation.

Although some interference and a not so low detection limit is observed, considering a DPASV procedure, the results point out for an application of the modified silica as an electrode modifier to be used in the electroanalytical techniques.

\section{Acknowledgements}

Authors are indebted to the Brazilian agencies $\mathrm{CNPq}$ and CAPES for GM and IC fellowship respectively and FAPESP for the financial support (03/02630-0, 05/04297-1) and MSc. Roni Vicente Reche do Laboratório para o Desenvolvimento da Química de Aguardente do IQSC/USP, by cachaça samples with known copper(II) contents.

Received 07 February 2007

Accepted 18 May 2007

\section{References}

[1] D. E. De Vos, M. Dams, B. F. Sels, P. A. Jacobs, Chem. Rev. 102 (2002) 3615.

[2] D. Zhao, J. Feng, Q. Huo, N. Melosh, G. H. Fredrickson, B. F. Chmelka, G. D. Stucky, Science 279 (1998) 548.

[3] D. Zhao, Q. Huo, J. Feng, B. F. Chmelka, G. D. Stucky, J. Am. Chem. Soc. 120 (1998) 6024.

[4] B.-G. Park, W. Guo, X. Cui, J. Park, C.-S. Ha, Microporous Mesoporous Mater. 66 (2003) 229.

[5] S. Inagaki, S. Guan, Y. Fukushima, T. Ohsuna, O. Terasaki, J. Am. Soc. 121 (1999) 9611.

[6] Y. Shan and L. Gao, Mater. Chem. Phys. 89 (2005) 412.
[7] A. Walcarius, Electroanalysis 8 (1996) 971.

[8]A. Walcarius, Chem. Mater. 13 (2001) 3351.

[9] S. V. Prabhu, R. P. Baldwin, L. Kryger, Anal. Chem. 59(1987) 1074.

[10] T. Molina-Holgado, J. M. Pinilla-Macias, L. Hernández-Hernández, Anal. Chim. Acta 309 (1995) 117.

[11] B. Ogorevc, X. H. Cai, I. Grabec, Anal. Chim. Acta 305 (1995) 176.

[12] M. F. Mousavi, A. Rahmani, S. M. Golabi, M. Shamsipur, H. Sharghi, Talanta 55 (2001) 305.

[13] N. L. Dias Filho, L. Caetano, D. R. Carmoa, A. H. Rosa, J. Braz. Chem. Soc. 17 (2006) 473.

[14] V. Beni, V. I. Ogurtsov, N. V. Bakunin, D. W. M. Arrigan, M. Hill, Anal. Chim. Acta 552 (2005) 190.

[15] J. Buffle and M.-L. Tercie, Trends in Anal. Chem. 24 (2005) 172.

[16] D. G. Barceloux, Clin. Toxicol. 37 (1999) 217.

[17] M. Etienne, J. Bessiere, A. Walcarius, Sens. Actuators B 76 (2001) 531.

[18] Ministério da Agricultura; Complementação de Padrões de Identidade e Qualidade para Destilados Alcóolicos; Portaria n ${ }^{\circ} 371$; Brasília 1974.

[19] P. J. S. Barbeira, L. H. Mazo, N. R. Stradiotto, Analyst 120 (1995) 1647.

[20] F. N. Crespilho, R. A. Messias, M. O. O.

Rezende, Anais da Associação Brasileira de

Química

$51(2002) 63$.

[21] J. R. Matos, L. P. Mercuri, M. Kruk, M. Jaroniec, Chem. Mater. 13 (2001) 1726.

[22] G. Marino, M. F. Bergamini, M. F. S. Teixeira, E. T. G. Cavalheiro, Talanta 59 (2003) 1021.

[23] G. Marino, I. Cesarino, E. T. G. Cavalheiro, Acaij 2 (2006) 37.

[24] B. D. Ripley and M. Thompson, Analyst 112 (1987) 377.

[25] D.C. Harris, Quantitative Chemical Analysis, $4^{\text {th }}$ Edition, Freeman, New York, 1995, p. 66. 